\title{
Towards improving the physical basis for ice-dynamics models
}

\author{
J. A. Richter-Menge \\ U.S. Army Cold Regions Research and Engineering Laboratory, Hanover, NH 03755, U.S.A.
}

\begin{abstract}
In situ measurements of ice stress were made on a multi-year floe in the Alaskan Beaufort Sea over a 6 month period, beginning in October 1993. The data suggest that, in this region of the Arctic during this experiment, there were two main sources of stress: a thermally induced stress caused by changes in air temperature, and a stress generated by ice motion. Due to the natural damping of the snow and ice above the sensor, the thermally-induced stresses are low frequency (order of days). Stresses associated with periods of ice motion have both a high-frequency (order of hours), and low-frequency, content. The relative significance of these sources of stress is seasonal, reflecting the changes in the strength and continuity of the pack.
\end{abstract}

\section{INTRODUCTION}

An important process to consider in the development of climate-change models is the dynamics of the sea-ice cover, since it impacts directly on the interaction of the ocean and atmosphere. Large-scale sea-ice dynamics models that are currently available have been formulated to reproduce the basin-wide pack-ice motion as indicated by drifting buoys and submarine-based ice-thickness measurements. The factors controlling ice deformation in these models, like the ice rheology, have been parameterized to produce accurate results at this scale (Hibler, 1986; Overland and Pease, 1988; Pritchard, 1988; Ip and others, 1991). These approximations are not founded on a thorough understanding of the basic physical processes involved in ice deformation. In the case of the ice rheology, for instance, no direct measurements of the stress as a function of deformation have been made to evaluate the assumed parameterizations. This approach can limit the usefulness of these modeling products in an application like climate studies, which involve long-term predictions of the behavior of the ice cover under significantly varying forcing conditions. Improving the physical basis of sea-ice dynamics models is a critical step towards increasing confidence in their predictive forecasting capabilities.

Ice stress and deformation measurements were collected concurrently during the recent Sea Ice Mechanics Initiative (SIMI), and can play an important role in developing our understanding of the deformation process. Ultimately, these data may provide the foundation for a physically based ice rheology that can be incorporated into sea-ice dynamics models. In this paper a 6 month stress time series is presented to illustrate the general characteristics and seasonal variations of pack-ice stress in the Alaskan Beaufort Sea. Potential sources for the stress are discussed, along with an approach for further exploration and modeling of the relationship between ice stress and deformation.

\section{FIELD MEASUREMENTS}

The objective of the SIMI program was to investigate the mechanical behavior of sea ice over a wide range of scales, from $10^{-2}$ to $10^{5} \mathrm{~m}$. As part of this effort, a 6 month field program was conducted in the Alaskan Beaufort Sea. The field camp was established in late September 1993 on a $2 \mathrm{~km}$ multiyear floe located approximately $450 \mathrm{~km}$ from the coast, at $75^{\circ} \mathrm{N} 147^{\circ} \mathrm{W}$. The field program ended in early April 1994. During this period, the floe drifted approximately $250 \mathrm{~km}$ to the west, reaching $74^{\circ} \mathrm{N} 155^{\circ} \mathrm{W}$. The most pronounced times of westward drift occurred during December and January.

Previous studies on pack-ice stresses have provided valuable information about the characteristics of ice stress at the center of a floe (Croasdale and others, 1988; Comfort and Ritch, 1990; Comfort and others, 1992) and at the edge of a floe (Tucker and Perovich, 1992). These investigations, combined with the finite-element model results of Frederking and Evgin (1990), suggested that boundary conditions, the distribution of applied loads, and the process of stress attenuation play an important role in defining ice stress at a point in a floe. The focus of the current investigation was to provide a more comprehensive look at the spatial and temporal distribution of stresses on a multi-year floe. An array of 29 in situ stress sensors were installed on the multiyear floe that served as the SIMI base camp. The sensors were deployed at five sites, including three locations around the perimeter of the floe and one at the center (Fig. 1).

The sensor used in this study was designed by Johnson and Cox (1982) to measure stresses in sea ice. It is a thickwalled, cylindrical steel annulus, sealed at both ends, that is $0.25 \mathrm{~m}$ long, with a $57 \mathrm{~mm}$ outer diameter and $25 \mathrm{~mm}$ inner diameter. A detailed description of the sensor, the theory behind its design, and the laboratory calibration tests can be found in Cox and Johnson (1983). Briefly, stresses in the ice are determined by measuring the radial deformation of the annulus, using a $120^{\circ}$ rosette of three vibrating wires stretched across the hollow center at the midpoint along its 


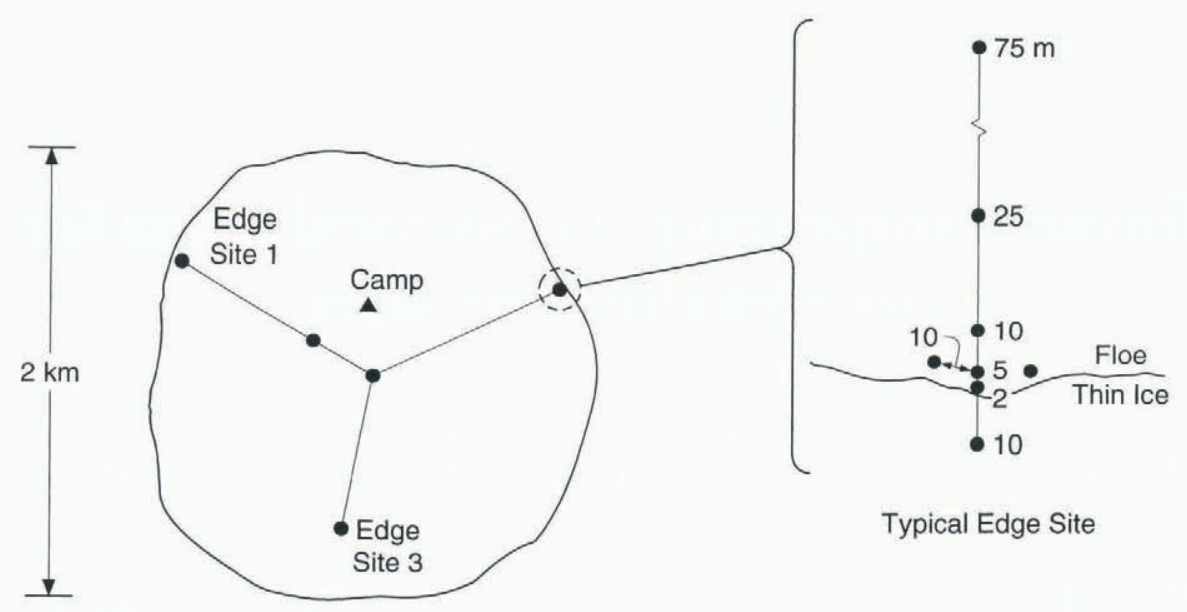

Fig. 1. Location of stress sensors on the multi-year floe.

length. Changes in the diameter of the annulus cause a change in the frequency of vibration of each wire. Knowing the material properties of the steel annulus, this change in frequency can be directly related to the stress applied to the sensor. The resolution of the stress gauge is $20 \mathrm{kPa}$. In-ice calibration tests indicate that, over a loading range of $0-2$ $\mathrm{MPa}$, the measurement of the principal stress components is accurate to within $\pm 15 \%$ of the applied stress and the direction of the principal stress is typically correct to within $\pm 5^{\circ}$. The sensor is also equipped with a thermistor, to measure the ice temperature at the location of the wire rosette.

Each stress sensor was installed by suspending it in a hole drilled in the ice cover. The hole was either drilled through the ice cover, so that it would backfill with sea water, or fresh water was poured into it. The sensor was then left to freeze in place, a process that took a maximum of 5 days, including the time for the dissipation of stresses associated with freeze-in. All but three of the sensors were located at approximately the same horizontal level in the ice sheet, with the wire rosette an average of $22.1 \mathrm{~cm}$ below the ice surface. The other three sensors were located deeper in the ice floe, which had an average thickness of $1.45 \mathrm{~m}$ in late-November. Data from the sensors were collected at 5 minute intervals for the entire 6 month program.

\section{RESULTS AND DISGUSSION}

The stress measurements provided information on the temporal and spatial variability of pack-ice stresses from the end of fall freeze-up through to the winter. A stress time series from a sensor located at edge site 3 is presented in Figure 2a to illustrate the typical characteristics of pack-ice stress. This sensor was located $402 \mathrm{~m}$ from the edge of the floe. It is apparent that the major $\left(\sigma_{1}\right)$ and minor $\left(\sigma_{2}\right)$ principal stresses both have a low-frequency (order of days, $\mathrm{Od}$ ), and high-frequency, (order of hours, Oh) content. The high-frequency component is much more evident and persistent in the major principal stress. During periods when there is little high-frequency content, the major and minor principal stresses are essentially equal. Tucker and Perovich (1992) found similar results for sea ice in the eastern Arctic. This observation suggests that during periods of predominantly low-frequency activity the stress in the ice is hydrostatic in the plane of the ice sheet.

The relative distribution of the high- and low-frequency content of the major principal stress exhibited significant spatial variability over the region of the floe. At edge site 3 the high-frequency component dominated the major principal stress over much of the experiment, generating the widest range of observed stress, from a compressive stress of $275 \mathrm{kPa}$ to a tensile stress of $20 \mathrm{kPa}$ (Fig. 2a). These magnitudes are consistent with those measured near the edge of a multi-year floe by Tucker and Perovich (1992). At edge site 1, located right at the edge of the floe (Fig. 1), the high-frequency content was still persistent in the major principal stress component, but it did not dominate the stress signal. The magnitude of the compressive stress during periods of significant high-frequency activity at edge site 1 was about a third of that measured at edge site 3 . At the site located in the center of the floe, the major principal stress was dominated by the low-frequency component and ranged from $100 \mathrm{kPa}$ compression to $50 \mathrm{kPa}$ tension. The minor principal stress showed little variation from site-to-site, with a strong low-frequency component that varied from $75 \mathrm{kPa}$ compression to $50 \mathrm{kPa}$ tension.

Three sources of stress were identified by Tucker and Perovich (1992) based on the measurements made in the eastern Arctic: thermally induced stresses originating from changes in the air temperature; dynamic stresses resulting from motion of the ice, which is primarily driven by winds and current; and stresses caused by tidal or inertial oscillations. The tidal or inertially induced stresses measured by Tucker and Perovich (1992) became evident as the instrumented floe entered shallow waters near an island. These stresses were easily detected in a spectral analysis of their data by a well-defined peak in the power spectrum at a period of about 12 hours. A similar analysis of the SIMI data produced no strong peaks at this period, indicating that during this experiment tidal or inertial oscillations were not a significant source of stress.

Thermally and ice-motion-induced stresses were apparent during the experiment. The reason that changes in the air temperature cause stresses to develop in multi-year ice has been described by a number of investigators, including Evans and Untersteiner (1971) and Lewis (1993). Thermal stresses are generated because the change in air temperature affects the top surface of the ice first, and then propagates downward through the sheet, causing differential expansion and contraction in the ice layers. Significant changes in the air temperature often occur over a period of a few hours. These rapid $(\mathrm{Oh})$ variations were observed during SIMI, typically ranging from $15-20^{\circ} \mathrm{C}$ and reaching a maximum of $30^{\circ} \mathrm{C}$ (Fig. 2b). Concurrent measurements of the ice 

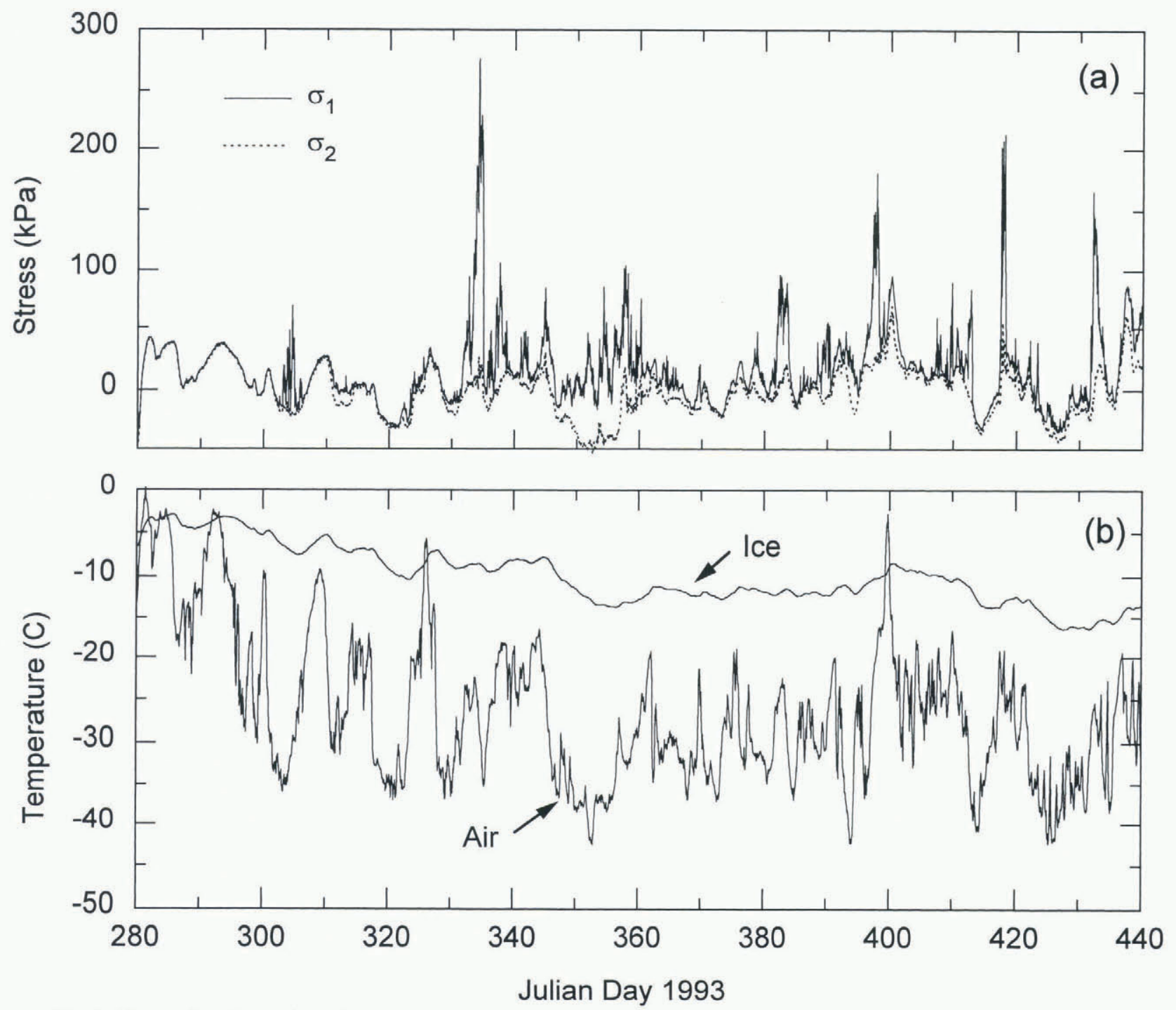

Fig. 2. Time series of $(a)$ the major $\left(\sigma_{1}\right)$ and minor $\left(\sigma_{2}\right)$ principal stresss and $(b)$ the air and ice temperatures at a sensor located at edge site 3,402 $\mathrm{m}$ from the edge of the $2 \mathrm{~km}$ diameter floe. The sensor measured stress and ice temperature at a depth of $20 \mathrm{~cm}$ below the ice cover. Positive stresses are compressive.

temperature at the sensor, $20 \mathrm{~cm}$ below the ice surface, show the damping effect of the snow and ice cover. In the ice, temperature fluctuations occurred over days rather than hours, and the magnitude of the variations was significantly reduced, to $5-10^{\circ} \mathrm{C}$.

Stresses caused by ice motion are distinguishable by their high-frequency content, which has been associated with the ridging, rubbling and lead-opening events that occur when the pack moves (Croasdale and others, 1987; Coon and others, 1989; Comfort and Ritch, 1990; Comfort and others, 1992; Tucker and Perovich, 1992). Comparison of the SIMI stress time series with visual observations of dynamic events on and around the floe during our experiment indicate the same association.

There is a notable change in the characteristics of the stress time series at edge site 3 around day 330 (26 November) (Fig. 2). Before day 330, the low-frequency content of both the major and minor principal stresses is clearly evident, with the two stress components equal over nearly the entire period. There is only one isolated interval of significant, high-frequency stress (between day 303 and day 307). After day 330, the high-frequency component dominates the major principal stress. The magnitude of the high-frequency variations is often $50-150 \mathrm{kPa}$ and reaches a peak of $250 \mathrm{kPa}$. These rapid changes in stress magnitude are superimposed on lower-frequency and lower-magnitude variations. During the periods of high-frequency stress, there is also significant deviation between the magnitudes of the major and minor stresses. This is most apparent from day 348 to day 356.

Cross correlations of the ice temperature and the major and minor principal stresses were conducted to confirm quantitatively a change in the characteristics of the stress at day 330. Correlations were performed over the entire measurement record, and for the periods before and after day 330. A 40 day high-pass filter was applied to the ice temperature and stress data before running the correlations to remove long-term seasonal variations, most evident in the ice temperature time series. The details of the filter are described in Hibler (1972).

The results of the correlation analysis are presented in Table 1, including the peak correlation coefficient and the lead/lag time. There is a strong and consistent correlation between the minor principal stress and ice temperature for the three periods considered, with a peak coefficient ranging from 0.89 to 0.81 . This suggests that the minor principal stress is a good indicator of the stresses caused by changes in the ice temperature, even during periods of ice-motioninduced stress activity.

The peak correlation coefficient for the major principal 
Table 1. Results of cross-correlation analysis of the ice temperature and stress

\begin{tabular}{|c|c|c|c|c|}
\hline \multirow[b]{2}{*}{$\begin{array}{l}\text { Period of } \\
\text { correlation }\end{array}$} & \multicolumn{2}{|c|}{ Major principal stress } & \multicolumn{2}{|c|}{ Minor principal stress } \\
\hline & $\begin{array}{l}\text { Correlation } \\
\text { coefficient }\end{array}$ & Lead time & $\begin{array}{l}\text { Correlation } \\
\text { coefficient }\end{array}$ & Lead time \\
\hline
\end{tabular}

(d)

(d)

$\begin{array}{lllll}\text { Day } 285-430 & 0.30 & 0.8 & 0.84 & 0.8 \\ \text { Day 285-330 } & 0.68 & 1.0 & 0.89 & 0.8 \\ \text { Day 330-430 } & 0.24 & 0.8 & 0.81 & 0.8\end{array}$

stress varies significantly, depending on the period of correlation. For the entire measurement period the coefficient is 0.30 , demonstrating that the major principal stress and temperature are not well correlated. The strength of the correlation between the major stress component and ice temperature improves significantly (to 0.68 ) for the period between days 285 and 330. In all cases, the stress leads the temperature by about a day, because the stress within the ice sheet begins to build as soon as the temperature change is felt at the top surface of the ice sheet. The change in temperature itself is not recorded by the thermistor in the stress sensor until the pulse generated by the temperature change reaches the sensor, $20 \mathrm{~cm}$ below the ice surface.

Further analysis was conducted to investigate the source of the low-frequency content of the major principal stress after day 330. A 2 day low-pass filter was applied to the major principal-stress record, removing the high-frequency content, and these data were cross correlated with the ice temperature. This analysis produced a peak correlation of 0.25 , which is essentially equal to the correlation coefficient of 0.24 determined for the major principal stress and ice temperature without the low-pass filter (Table 1). This shows that the lower-frequency component of the major principal stress is not strongly associated with the thermal loading of the ice sheet and, therefore, there must be a low-frequency component $(\mathrm{Od})$, in the ice-motion-induced stress.

The result of a consistently strong correlation of the minor principal stress coupled with the consistently weak correlation of the major principal stress with ice temperature after day 330 further suggests that ice-motion-induced stress is non-hydrostatic. The characteristics exhibited in the stress time series of the major principal stress direction, $\theta_{1}$, are consistent with this observation. In Figure $3, \sigma_{1}$ and $\theta_{1}$ are shown from day 350 to 390 for the sensor located $402 \mathrm{~m}$ from the ice edge at edge site 3 . It is apparent that during periods of high-frequency activity, $\theta_{1}$ shows strong directionality, for example days 350-362 and days 382-385. When the major and minor principal stress components are equal (days $371-$ $372), \theta_{1}$ varies widely. Additional work will be conducted to confirm and characterize the low-frequency content of the motion-induced stress and its source.

\section{SUMMARY AND FUTURE WORK}

These results suggest that during the SIMI experiment there were two primary sources of stress in the central Arctic changes in ice temperatures and ice motion - and that their relative roles were seasonally dependent. In the fall and early winter, the thermally induced stress was dominant, producing a hydrostatic stress with a variation fre- quency of Od. Isolated ice-motion-induced stress events occurred during this period, and were easy to distinguish by their high-frequency content $(\mathrm{Oh})$. In late-November the ice-motion-induced stress became nearly continuous in the stress time series and, near the edge of the floc, dominated the record.

This significant change in the characteristics of ice stress may mark the transition of the ice pack to a mechanical continuum. In the early fall, there is apparent continuity in the pack because the open water has frozen over and the ice concentration is near $100 \%$. The new ice that has formed between the thick floes is thin and easily deformed, however, and cannot effectively transmit stresses caused by the largescale ice motion. As the season progresses, the new ice becomes stiffer and stronger, developing an ice cover that can transmit these stresses over distances greater than a floe. In the case of this experiment, while there was little open water in the vicinity of the SIMI camp in late-September, the transition to a mechanical continuum did not occur until late-November. It is expected that, in the spring, as the ice warms and thins, this process will reverse itself.

The ice-motion-induced stress events appear to generate a non-hydrostatic stress with both a high- and low-frequency content. It is likely that the high-frequency component originates from discrete failure processes, like the formation of a ridge, rubble field or lead. The low-frequency component may be associated with the gradual increase in stress that develops from the large-scale motion of the pack during the event and, therefore, may correspond to the internal ice-stress term in the momentum-balance equation typically used in basin-scale sea-ice dynamics models (Hibler, 1986). The link between the two frequency components may be that the discrete failure processes act to strengthen the pack by removing areas of weakness during these periods of large-scale ice motion.

These observations, while based on the analysis of a comprehensive set of field measurements, are speculative and require further investigation to determine their accuracy. Of particular interest is developing a more definitive understanding of the relationship between ice stress and deformation, or the ice rheology. Ice motion is the source of stress considered in rheology, so it will be necessary to develop a technique to remove the thermally induced stress from the records. Since the minor principal stress is strongly correlated to the thermal loading of the ice and the icemotion-induced stress is non-hydrostatic, it may be possible to obtain a good first approximation of the ice-motion-induced stress by subtracting the minor from the major principal stress. Once the ice-motion-induced stress is isolated, a comparison of the time series of the motion-induced stress to the concurrent records of deformation can be made. The deformation data are available from a set of position buoys located in $10 \mathrm{~km}$ and $20 \mathrm{~km}$ rings centered on the floe that served as a base for the experiments, and from SAR satellite imagery. Identifying the individual processes governing pack-ice failure is a particular area of interest. Once identified, these processes can be parameterized and incorporated into a model of the pack ice to confirm and further assess their role.

A granular sea-ice model, which represents the ice pack as discrete elements of multi-year and first-year ice divided by leads and pressure ridges, will be used for this phase of the investigation (Hopkins, 1996). Since this model embodies the granular nature of the ice pack, the important 

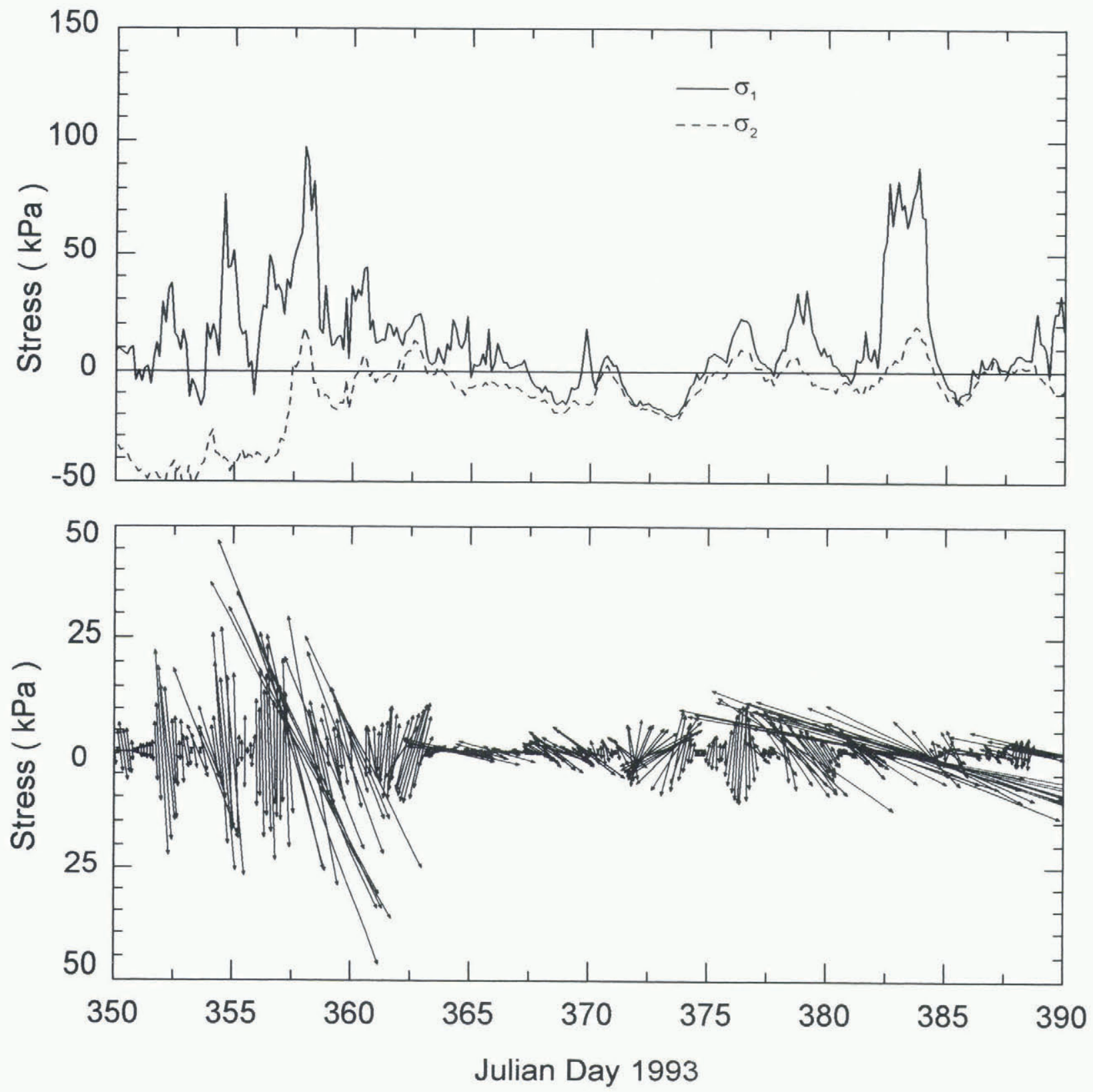

Fig. 3. Magnitude $\left(\sigma_{1}\right)$ and direction $\left(\theta_{1}\right)$ of the major principal stress at a sensor located at edge site 3,402 $\mathrm{m}$ from the edge of the floe. $\theta_{1}$ is measured from the vertical, which corresponds to the direction along the line between edge site 3 and the stress-sensor site at the center of the floe ( see Fig. 1).

effects of the spatial distribution of ice thickness and the anisotropic distribution of leads are inherently included. The initial spatial configuration of the model will be established using SAR imagery and SIMI ground records. The model ice pack will be driven by forcing fields derived from the meteorological and ocean-current data collected during SIMI. The general characteristics of the stress and deformation predicted by the model will be compared to the SIMI records and SAR images to evaluate the model.

Once the accuracy of the assumptions and the granular sea-ice model are satisfactory, the model can be used further to improve an understanding of sea-ice rheology and the ability to model it. A continuum description of the sea-ice rheology can be obtained by averaging the results over the domain of the simulation. This ice rheology can then be applied to continuum-based models. The influence of the ice-thickness distribution on the deformation process can be evaluated using the granular model. The granular model can also serve as a vehicle for testing parameterizations of important small-scale processes for use in larger scale modcls.

\section{ACKNOWLEDGEMENTS}

I would like to thank B. Elder for his help in executing this field program and providing assistance in the data analysis and M. Hopkins, D. Perovich and S. Ackley for many insightful discussions. This work was supported by the High Latitudes Dynamics Program of the Office of Naval Research.

\section{REFERENCES}

Comfort, G. and R. Ritch. 1990. Field measurement of pack ice stresses. In Ayorinde, O. A., N. K. Sinha and D. S. Sodhi, eds. Proceedings of the Ninth International Conference on Offshore Mechanics and Arctic Engineering - 1990. Vol. IV. Artic/Polar Technology. New York, American Society of Mechanical Engineers, 177-181.

Comfort, G., R. Ritch and R. M.W. Frederking. 1992. Pack ice stress measurements, In Ayorinde, O. A., N. K. Sinha, D. S. Sodhi and W. A. Nixon. eds. Proceedings of the 11th International Conference on Offshore Mechanics and Arctic Engineering - 1992. Vol. IV. Arctic/Polar Technology: New York, American Society of Mechanical Engincers, 245-253.

Coon, M. D., P. A. Lau, S. H. Bailey and B. J. Taylor. 1989. Observations of ice 
floe stress in the eastern Arctic. In Axelsson, K. B. E. and L. A. Fransson, eds. POAC 89. The 10th International Conference on Port and Ocean Engineering under Arctic Conditions, June 12-16 1989, Luleä, Sweden. Proceedings. Vol. 1. Luleå, Tekniska Högskolan i Luleă, 44-53.

Cox, G. F. N. and J. B. Johnson. 1983. Stress measurements in ice. CRREL Rep. 83-23.

Croasdale, K. R., G. Comfort, R. Frederking, B.W. Graham and E. L. Lewis. 1988. A pilot experiment to measure Arctic pack-ice driving forces. In Sackinger, W. M. and M. O. Jeffries, eds. Ninth International Conference on Port and Ocean Engineering under Arctic Conditions, August 17-21, 1987, Fairbanks, Alaska. Proceedings. Vol. III. Fairbanks, AK, University of Alaska. Geophysical Institute, 381-395.

Evans, R. J. and N. Untersteiner. 1971. Thermal crack in floating ice sheets. 7. Geophys. Res., 76 (3), 694-703.

Frederking, R. M.W. and E. Evgin. 1990. Analysis of stress distributions in an ice floe. In Ayorinde, O. A., N. K. Sinha and D. S. Sodhi, eds. Proceedings of the Ninth International Conference on Offshore Mechanics and Artic Engineering - 1990. Vol. IV. Arctic/Polar Technology. New York, American Society of Mechanical Engineers, 83-87.
Hibler, W. D., III. 1972. Design and maximum error estimation for small error low-pass filters. CRREL Rep. 304.

Hibler, W. D., III. 1986. Ice dynamics. In Untersteiner, N., ed. Geophysics of sea ice. London, etc., Plenum Press, 577-640. (NATO ASI Series B: Physics 146.

Hopkins, M. A. 1996. On the mesoscale interaction of lead ice and floes. $\mathcal{J}$. Geophys. Res., 101 (C8), 18,315-18,326.

Ip, C. F., W. D. Hibler, III and G. M. Flato. 1991. On the effect of rheology on seasonal sea-ice simulations. Ann. Glaciol., 15, 17-25.

Johnson, J. B. and G. F. N. Cox. 1982. Stress sensor particularly suited for elastic, plastic, and viscoelastic materials. United States Patent $4,346,600$, 31 August 1982.

Lewis, J. K. 1993. Model for thermally-induced stresses in multi-year sea ice. Cold Reg. Sci. Technol., 21 (4), 337-348.

Overland, J. E. and C. H. Pease. 1988. Modeling ice dynamics of coastal seas. 7. Geophys. Res., 93 (C12), 15,619-15,637.

Pritchard, R.S. 1988. Mathematical characteristics of sea ice dynamics models. 7. Geophys. Res., 93 (C12), 15,609-15,618.

Tucker, W. B., III and D. K. Perovich. 1992. Stress measurements in drifting pack ice. Cold Reg. Sci. Technol., 20 (2), 119-139. 